\title{
Strategic Use of Role Playing in a Training Workshop for Chemistry Laboratory Teaching Assistants
}

Priyanka Lekhi and Sophia Nussbaum

University of British Columbia

\begin{abstract}
Many Canadian universities have created professional development programs for their teaching assistants (TA) but may be uncertain about how to bridge the gap between TAs' knowledge of effective teaching strategies and TAs' confident applications of these strategies. We present a technique used in a two-day training workshop to enhance graduate students skills in using effective teaching strategies: role playing. This paper outlines a framework that includes five key elements (Icebreaking, Shared Experiences, Modelling, Acting and Debriefing) to strategically design role playing activities in a training program. We describe each of the 5 elements and explain how they support training through role play exercises. Participant written feedback collected in 2010, 2011, 2012 and 2014 suggested that role playing was a useful and enjoyable technique. Pre and post workshop questionnaire data suggested that self-perceived competencies for specified tasks directly connected to a role play activity promoted greater positive differences between the pre and post groups compared to self-perceived competencies for specified tasks not directly connected to a role play activity. Based on these results, we assert that training programs which rely on strategic role playing activities will lead to a better overall TA experience of the training program and improvements in TAs' self-perceptions of certain teaching competencies.
\end{abstract}

\section{Résumé}

Bien que plusieurs universités canadiennes aient créé des programmes de perfectionnement professionnel pour leurs auxiliaires à l'enseignement, il peut être difficile pour ces auxiliaires d'appliquer avec confiance les techniques d'enseignement efficace qu'ils ont apprises. Nous avons donc intégré le jeu de rôles à un atelier de deux jours suivi par des étudiants diplômés afin 
d'améliorer leur stratégies d'enseignement. Le présent article illustre les cinq principes essentiels qui permettent d'inclure le jeu de rôles de façon stratégique en contexte de formation : brise-glace, partage d'expériences, modélisation, pratique par le jeu et compte rendu. Nous décrivons ces cinq éléments et expliquons comment, par des jeux de rôles, chacun est utile à la formation. Les remarques écrites soumises par les participants des ateliers de 2010, 2011, 2012 et 2014 soutiennent l'idée que le jeu de rôle est un outil d'apprentissage à la fois utile et agréable. Remplis avant et après la séance de formation, les réponses aux questionnaires d'auto-évaluation des aptitudes personnelles démontrent une meilleure évolution des habiletés présentées avec une activité de jeu de rôles, comparativement à celles exposées sans cette composante. De par ces résultats, nous établissons que l'emploi stratégique du jeu de rôles lors de séances de formation mène à une meilleure expérience pour les auxiliaires à l'enseignement, en plus d'améliorer leur auto-perception de certaines compétences en enseignement.

\section{Introduction}

Professional development programs for teaching assistants (TAs) are essential to a quality undergraduate education (Piccinin, Farquharson, \& Mihu, 1993). Several studies of TA training programs have been conducted but few have discussed specific techniques aimed at enhancing TA skills in a laboratory setting. Research on undergraduate education demonstrates the benefits of student-centred activities such as peer instruction, and group work with a focus on problem solving and making connections to the real world (Bransford, Brown, \& Cockings, 2000; Deslauriers, Schelew, \& Wieman, 2011; Mazur, 2009). Perhaps it is time for TA-centered training for TAs. Indeed, active learning and experiential methods are beneficial to training TAs (Meyers, 2001; Meyers \& Prieto, 2000). A key consideration for TA training programs is that not only do we, as instructors, want TAs to know specific teaching strategies, we also want the TAs to actually use those strategies effectively while they are teaching. For example, it is beneficial if a TA is able to recognize that asking appropriate questions promotes critical thinking in undergraduate students. It is more important that the TA asks the students questions, which promotes critical thinking. Because of the specific skills TAs need when teaching, the more applicable the training, the more likely it is that those skills will be acquired (Wimer, Prieto, \& Meyers, 2004). Hence, our chemistry TA training program for new TAs in the firstyear laboratory course uses a variety of techniques such as brainstorming, discussing case studies, and doing group work. It also requires TA participants to role-play specific teaching strategies in common scenarios that TAs face in the laboratory setting.

Role playing has been used as an instructional strategy for many years and over a wide range of educational levels (Fadali, Robinson, \& McNichols, 2000; Van Ments, 1999). Role playing can be described as a technique which "enables learners to engage in experience, albeit pretend experience" with learners acting out roles in case scenarios to provide practice and feedback (Kiger, 2004., p. 124). The benefits of role playing for developing skills, knowledge, and attitude have been seen within undergraduate education (DeNeve \& Heppner, 1997; Francis \& Byrne, 1999; Sturges, Maurer, \& Cole, 2009) and in therapeutic and management training settings (Lane, Hood, \& Rollnick, 2008; Sogunro, 2004). Sogunro 
(2004) highlights the importance of role playing to transform theoretical principles into an experiential format for training future leaders in a management program. Role plays enable students to put themselves in situations they have never experienced, where they can empathize with and understand other people's motivations (Van Ments, 1999), and this has the potential to lead to behavioural and attitudinal changes (Turner, 1996). Although the technique is widely used, the success of role playing depends on its strategic use (Joyner \& Young, 2006; Van Ments, 1999; Wedig, 2010). Specifically, the role play activity requires a planned and purposeful set-up and debrief to be most effective (Joyner \& Young, 2006).

This paper reports on a training program for chemistry laboratory TAs that relies on strategic role playing activities. The role playing activities involve five key elements meant to bridge the gap between TAs' learning of effective teaching strategies and TAs' confident use of those strategies.

\section{Program Structure}

Every September since 2009, the Department of Chemistry at the University of British Columbia has welcomed approximately 35 to 50 new graduate students, most of whom will hold TA positions in the first-year undergraduate laboratory course. The department provides all new incoming TAs with a training program that includes an initial 2-day training workshop in the first week of classes followed by several 30- to 60-minute content-specific training sessions held during term. The program also includes a mentoring component in which TAs who are either self-identified or instructor-identified as requiring more professional development than the initial workshop are paired with a senior TA throughout the term. The 2-day workshop consists of interactive training sessions intended to enhance participants' teaching skills in chemistry and to provide the necessary background needed for the TA positions. The sessions explore the following topics: inquiry-based learning and questioning techniques, professionalism, best practices in grading, and working with culturally diverse students and colleagues. The participants are pre-assigned to diverse groups of four to six TAs. For each group, the goal is to have at least two females and no more than two participants with the same citizenship. Information regarding citizenship and gender is available prior to the workshop as a result of the application process.

The workshop begins with icebreaker activities so participants begin to know the other members of their group. During the workshop, TAs perform the first experiment to familiarize themselves with the laboratory equipment, the laboratory environment, and the learning goals. The first-year undergraduate laboratory course uses a mixed-mode guided inquiry approach (Minner, Levy, \& Century, 2010). In this approach, students are expected to come up with their own experimental design with support from online, written, and face-to-face resources. To ensure the success of this pedagogy for undergraduate students, proper professional development is needed for the TAs (Oliveira, 2010). Thus, in each training session, participants will apply the techniques learned to specific examples and scenarios TAs face in this lab course.

\section{Intended Program Outcomes}

The chemistry department has compiled a list of observable skills and attitudes that a laboratory TA should demonstrate. The training program aims to facilitate the development of the following skills and attitudes: 
- The TA promotes critical thinking by asking the students questions relevant to the techniques, reactions, and/or chemistry encountered during the course of the laboratory period. The TA guides students with questions towards the correct answer.

- The TA maintains a professional relationship with students and does not favor any one student or group of students.

- The TA is patient with students and offers different explanations if the student does not "get it" right away.

- The TA offers the appropriate amount of feedback on marked reports and other student submissions and keeps accurate, up-to-date grade records.

- The TA is consistent in marking and follows the established or self-created marking scheme or rubric.

- By being aware that cultural diversity has an impact on educational situations, TAs will use best practices when it comes to working with a culturally diverse body of students and colleagues.

\section{Strategic Use of Role Playing}

The success of the role playing technique depends on its strategic use (Joyner \& Young, 2006; Van Ments, 1999; Wedig, 2010) and on addressing the potential for anxiety and nervousness among participants. Our strategy for role plays in the initial 2-day TA training workshop relies on the following five elements which we refer to using the mnemonic: "Role playing is best when it IS MAD" (Icebreaking, Shared Experiences, Modelling, Acting and Debriefing):

1. Icebreaking to create a relaxed atmosphere. The TAs are all new graduate students, and many are international students. Each year, approximately 50\% of the new TAs are from Canada and the United States (the majority of this group are from Canada), with the remaining 50\% typically from China, India, Iran, and European countries (the majority of this group are from China). With such a diverse mix, it is essential to set aside time at the start of the workshop when TAs can introduce themselves and share perspectives. A common icebreaker we use is to ask the new TAs to share a good and a bad learning experience with their group members. Other teaching-related topics are discussed in small groups throughout the workshop and before the first role play. For example, one discussion topic is the role of TAs in promoting critical thinking in undergraduate students. Icebreakers relieve tensions between people, build trust, and foster a safe environment (Chlup \& Collins, 2010). Experiences positive emotions during learning leads to greater retention of skills and knowledge (Boud, Keough, \& Walker, 1996; Lane, et al., 2008). In the initial workshop, the participants spend 4 hours together in small groups before the first role play activity.

2. Applying the role plays to a shared experience. Because our TAs are new and come from around the world, it is difficult to create a role play of a teaching experience that is common among them. A scenario that is unfamiliar may lead to anxiety or to confusion during a role play exercise if each TA brings different assumptions about the scenario. In the initial TA training workshop, the TAs perform the first experiment in the first-year labs (which the incoming undergraduate students will be performing), and the role play scenarios are built around this first experiment. This way, TAs just arriving from China, for example will have a similar image of the laboratory setting as a TA whose undergraduate education may have been in the same department in which they are now 
working. Basing the role play on shared experiences is essential, particularly if the group consists of international TAs.

3. Facilitators modelling a role play. Before asking the participants to role-play for the first time, the facilitators of the workshop perform a role play themselves in front of the entire group. This shows collegiality between facilitators and participants and clarifies expectations of the activity.

4. Acting role plays in groups of two or three after discussing a teaching strategy. The first role play is done in pairs with no observers. The TAs turn to a partner and role-play a scenario where one person is the student and one person is the TA. Then they switch. The role plays are short, about 5 minutes or less. An example of a scenario is one where a student does not understand the purpose of adding a specific reagent in the first experiment. The TA is instructed to use questions to guide the student to the correct answer. After the first role play, groups of three TAs work together on a role play, with two actors and one observer. The observer provides feedback and alternative strategies for the TA to use in the scenario. The role plays are not done in front of larger groups. All small groups are applying the same teaching strategy but to different scenarios. The same or similar scenarios are used each year. The role plays are a chance for the TAs to practise incorporating a particular strategy into their teaching. For example, the TAs are told to guide students with questions when a student asks them a question, rather than just give the answer to a question. TAs accept that this strategy has benefits and identify the benefits. In the role play, the TAs practise using the strategy. Research indicates that the use of concrete and interactive activities such as role playing, after students have some prior knowledge of abstract concepts is effective in helping students understand concepts (Bybee \& Sund, 1982).

5. Debriefing the role play experience and encouraging reflection. It is important to debrief the role play exercise with the entire group of new TAs to acknowledge the challenges the TAs faced using the new strategy. It is not easy to change one's behaviour!

\section{Evaluation of Role Playing in the Program}

We collected data to measure the effectiveness of the initial TA training workshop but did not directly assess the effectiveness of role playing as a training technique. The feedback forms consisted of questions aimed at assessing the usefulness of the day's activities. Written feedback forms were collected each day during the initial 2-day workshop.

We also used pre and post questionnaires designed to evaluate changes in TAs' selfperceived competencies and attitudes after the initial 2-day workshop, and to investigate any cognitive gains from the workshop. The questionnaire consisted of open-ended questions and two sets of questions for which the responses produced ordinal data on a 5-point scale. The first question set asked TAs to rate how they feel about their upcoming TA duties, and the second question set asked TAs to rate their level of competency for each behaviour listed. The pre and post questionnaire data were unpaired and were compared to see if there was a difference between the pre and post groups in reported attitudes and self-perceived competency.

The pre and post questionnaires were analyzed for 2010, 2011, 2012 and 2014 (no questionnaire data were collected in 2013). In the first question set, participants were asked to rank their attitudes in different categories ranging from "Not at all" to "Moderately" to "Extremely". For analysis, rankings were grouped into three categories. Com- 
bining rankings was done to increase the number of counts per category for calculating a chi-squared value and to simplify the relationship between the categories. Scores of 1 and 2 were grouped into "Not at all", a score of 3 was its own category ("Moderately"), and scores of 4 and 5 were grouped into "Extremely". For the second question set, participants were asked to rank their level of competency in performing a series of tasks associated with teaching and learning. A 5-point scale was used ranging from "Beginning; ample guidance needed" to "Developing; some guidance needed" to "Exemplary; no guidance needed". For analysis, scores of 1 and 2 were grouped into "Beginning", a score of 3 was its own category ("Developing") and scores of 4 and 5 were grouped into "Exemplary".

The pre-questionnaire was filled out anonymously online by new TAs in August each year, and the post-questionnaire was filled out anonymously online within 10 days after the initial TA training workshop by the same set of TAs. Each year, the response rate for the pre-questionnaire was greater than the response rate for the post-questionnaire. A Pearson chi-square $\left(\chi^{2}\right)$ test was performed to assess the statistical difference between the pre and post groups, since the data are categorical.

\section{Results and Discussion}

\section{Written Feedback Forms}

In the written feedback form on Day 1 of the initial workshop, TAs were asked to identify the best part of the day. In 2010, the first time we used role plays, 11 out of 38 TAs (29\%) responded with "role playing." That same year, nine TAs (24\%) responded to this question by naming either the session on questioning techniques or the session on teaching techniques, both of which included role playing exercises. The other responses included "performing the experiment" (24\%), "meeting other TAs" (10\%), "lunch" (8\%), and "group discussions" (5\%). Between 2010 and 2014, the responses to the same question included similar themes with an overall $22 \%$ of 159 TAs identifying role playing as the best part of their day. If we include the responses that identified a session with a role playing activity, the percentage of participants doubles. When prompted to provide an explanation for their choice in the written feedback form, there were two themes: connecting knowing the technique to actually using it, and enjoyment. Specific responses included "role plays brought to light how difficult [it is] to put these concepts into practice"; "role playing made me feel like a TA"; " role plays was a preview to TAing"; and "role plays were fun". This feedback aligns with the purpose of using role plays in the training as a way to bridge the gap between knowledge of a teaching technique and actually using the technique. Moreover, in all the written feedback forms collected in these four years, not one participant included a critical comment about the role play activities in their response to the question asking about how the workshop could be improved. We attribute this to a positive training environment that supports role playing activities, an environment created by including the five elements as previously described ("IS MAD"). Other studies have highlighted the importance of debriefing role plays and providing explanations before a role play (Fadali et al., 2000; Van Ments, 1999). In this setting, when the participants do not know each other prior to the training and are from different backgrounds, it is also key to include icebreakers and to base the role plays on shared experiences. 


\section{Pre and Post Questionnaires}

Proportions (\%) for pre and post questionnaire responses for attitude and self-perceived competencies are presented in Table 1 and Table 2.

Table 1.

Summary of Attitudes Toward Upcoming TA Duties, in Response to the Question "When you consider the duties you will perform as a TA, to what extent do you feel each of the following?"

\begin{tabular}{|c|c|c|c|c|c|c|c|}
\hline \multirow[t]{2}{*}{ Attitude } & \multicolumn{3}{|c|}{$\begin{array}{l}\text { Proportion (\%) of Responses in } \\
\text { Pre-Training Questionnaire } \\
\qquad N=102\end{array}$} & \multicolumn{3}{|c|}{$\begin{array}{c}\text { Proportion (\%) of Responses in } \\
\text { Post-Training Questionnaire } \\
N=84 \\
\end{array}$} & \multirow[t]{2}{*}{$x^{2}$} \\
\hline & $\begin{array}{c}\text { Not At } \\
\text { All }\end{array}$ & Moderately & Extremely & $\begin{array}{c}\text { Not At } \\
\text { All }\end{array}$ & Moderately & Extremely & \\
\hline Anxious & 45 & 42 & 13 & 44 & 45 & 11 & $\begin{array}{c}0.27 \\
p=.873\end{array}$ \\
\hline Excited & 14 & 40 & 46 & 13 & 38 & 49 & $\begin{array}{c}0.14 \\
p=.933\end{array}$ \\
\hline Alone & 79 & 14 & 7 & 83 & 15 & 2 & $\begin{array}{c}3.63 \\
p=.163\end{array}$ \\
\hline Scared & 72 & 27 & 1 & 74 & 25 & 1 & $\begin{array}{c}0.16 \\
p=.925\end{array}$ \\
\hline Comfortable & 18 & 51 & 31 & 20 & 45 & 35 & $\begin{array}{c}0.62 \\
p=.734\end{array}$ \\
\hline Supported & 14 & 48 & 38 & 11 & 49 & 40 & $\begin{array}{c}0.40 \\
p=.818\end{array}$ \\
\hline Interested & 5 & 22 & 73 & 5 & 20 & 75 & $\begin{array}{c}0.05 \\
p=.973\end{array}$ \\
\hline Capable & 4 & 41 & 55 & 6 & 32 & 62 & $\begin{array}{c}1.80 \\
p=.408 \\
\end{array}$ \\
\hline
\end{tabular}

Note. Boldface indicates items with the largest (though still nonsignificant) differences between pre and post groups.

No items in Table 1 had statistically significant differences in categorical proportions between the pre and post groups ( $p>.05)$. However, differences between the pre and post groups for the items "Alone" and "Capable" were larger than for other items in the questionnaire (Table 1). The proportion of TAs that reported that they did not feel "alone" after the TA training workshop was greater after the workshop $\left(\chi^{2}(2)=3.63, p>.05\right)$. As well, the proportion of TAs that reported they felt extremely "capable" was greater after the workshop $\left(\chi^{2}(2)=1.80, p>.05\right)$.

The results in Table 2 show neutral or positive differences between the pre and post groups in self-perceived competency for all items. Although none of the differences were statistically significant ( $p>.05$ ), the items specifically linked to a role play activity in the workshop showed the largest difference as compared to the other items, with the exception of: "Approaching my TA supervisor for matters related to teaching that are beyond my job duties such as cheating," which was not paired with a role play activity. 


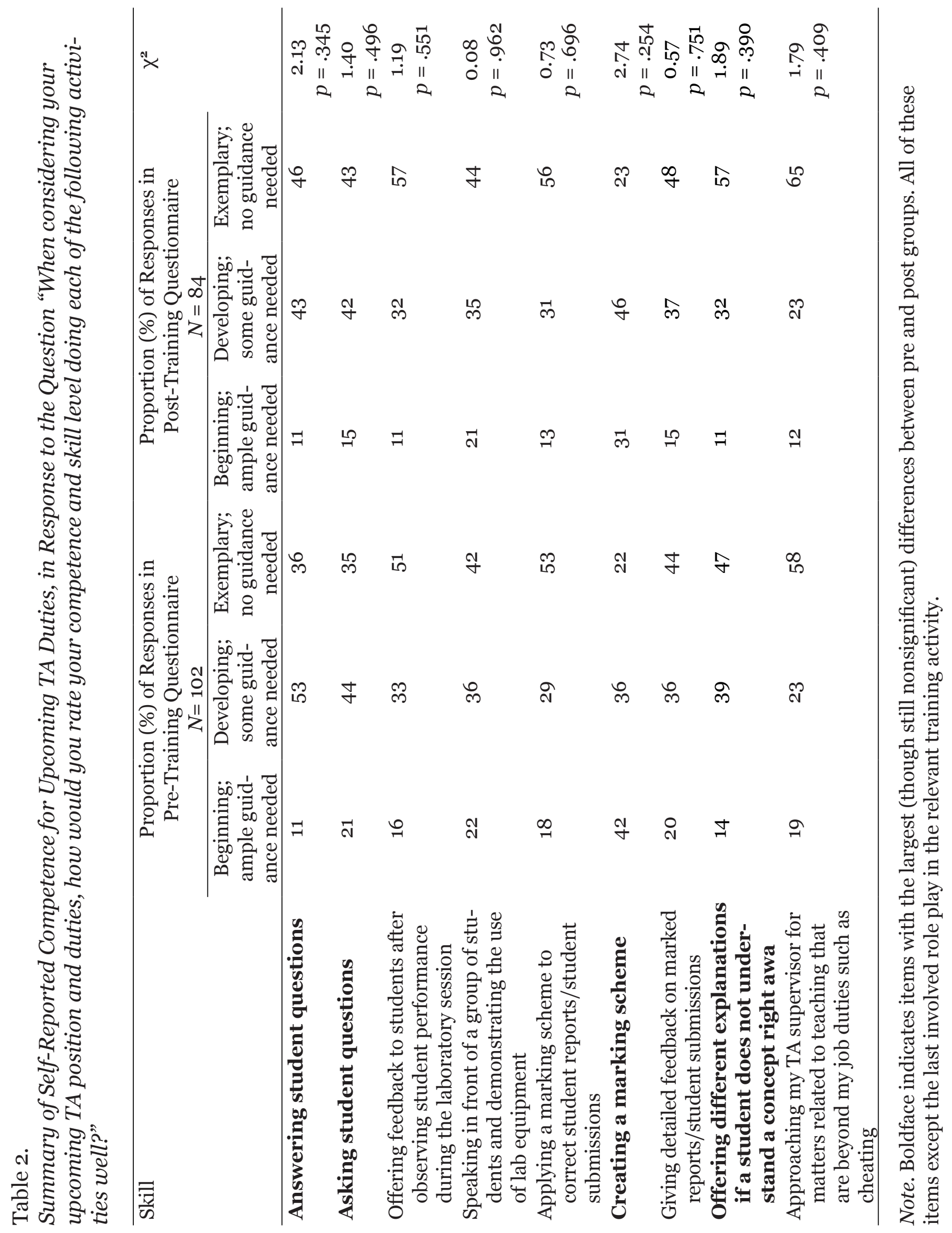


The four items that were paired with a role play activity in the initial workshop were "Answering student questions," "Asking student questions," "Creating a marking scheme," and "Offering different explanations if a student does not understand a concept right away." Participants were given scenarios to act out in pairs where one participant was the TA and one participant was the student. For example, each pair was tasked with role-playing a situation where a student is confused and asks the TA a question. The TA needed to use guiding questions to help the students arrive at the correct answer instead of simply answering the question (Oliveira, 2010). In another role play, the TA was tasked with asking a student probing questions when the TA noticed something incorrect in the student's laboratory notebook. There was also a role play activity where participants had to explain a concept multiple ways to a peer who was role-playing a student who did not understand the concepts that were being explained. Another role play had participants creating a marking scheme based on principles discussed in the workshop and role-playing that they were now defending the marking scheme to a student. These four items had $\chi^{2}(2)$ values ranging from 1.404 to $2.744,(p>.05)$ whereas "Speaking in front of a group of students and demonstrating lab equipment" was not role-played and the difference between the pre and post groups was much smaller $\left(\chi^{2}(2)=0.08, p>.05\right)$ (Table 2$)$. These results suggest that TAs selfperceptions of competencies improved when the competencies were linked to role playing activities compared to self-perceptions of competencies not linked to role playing activities.

\section{Limitations and Future Work}

One of the limitations of using a pre and post-test design in this setting is that the participants are new TAs and likely do not have an accurate perception of their upcoming TA tasks. Kruger and Dunning (1999) found that people who are unaware of their abilities tend to hold overly favourable views of their own competencies. Thus, the prequestionnaire may have overly favourable ratings because the TAs simply are not aware of the upcoming tasks and their abilities, and rate themselves more highly. This would lead to smaller calculated shifts between pre and post and could explain why the shifts are not statistically significant.

A key limitation of this study is the absence of a control group of TAs who did not participate in role playing exercises. Without a control group, it is unclear to what extent TAs who did not participate in role playing exercises show similar improvements in outcomes. Also, the pre- and post- questionnaires and feedback forms are evaluated the entire initial workshop, not only the role playing exercises. However, the role playing exercises were a key component of this workshop so any positive feedback must be attributed to them, at least partially. Furthermore, in the written feedback, TAs identified the role playing exercises as a key component of the workshop.

The pre and post questionnaires were completed by the TAs anonymously. In the future, it will be helpful to collect data with identifiers so the data can be paired. Furthermore, the outcomes of training were measured 1 week after the training through selfassessments. Observations of TA behaviour were lacking in this study. It is unclear as to what extent any gains persisted over time or transferred to actual classroom teaching.

Research suggests that continued practice and feedback are needed for sustained behaviour change (Weimer \& Lenze, 1997). In the next few years, we are planning on hiring upper-year undergraduate students to observe TAs while they are teaching. 


\section{Conclusions}

Using role play activities strategically in TA training programs leads to a better training experience for TAs and may be an effective way to bridge the gap between learning a technique and actually using the technique. We suggest incorporating five key elements when using role plays ("IS MAD"): Icebreakers are used to create a safe and comfortable atmosphere, the role plays are based on shared experiences, the facilitators model a role play, the role play is acted out in pairs and not observed initially, and the role play is debriefed. Our use of these five elements created a positive environment that supported the role play activities for training purposes, as evidenced by the participant responses in the written feedback forms. In feedback from diverse groups of TAs over a span of multiple years, role plays were consistently identified as the best part of the training day and were consistently absent from any criticism. TAs indicated that the role plays helped them to connect the teaching theories with practice. The questionnaire results suggest that competencies related to role playing activities led to greater positive pre and post differences in self-perceived competency than those not involving role playing, though these differences were not statistically significant. Thus, the inclusion of role playing activities in training may improve TAs' self-perceptions of certain competencies.

\section{Acknowledgements}

We would like to thank the Office of the Provost and VP Academic TA Training Funds at UBC for supporting our program and Dr. Catherine Rawn at UBC for providing guidance on the development of the questionnaires. A special thank you to Dr. Jacklyn Stewart at UBC for her feedback on the evaluation process and this paper. We would also like to acknowledge all the members of the Centre for Teaching, Learning and Technology (CTLT), Centre for Intercultural Communication (CIC) and Department of Chemistry who have co-facilitated the workshop over the years, as well as the first-year laboratory personnel and all chemistry TAs whose enthusiasm and dedication enable the training workshop to be successful and enjoyable to deliver every year.

\section{References}

Boud, P., Keough, R., \& Walker, D. (1996). Promoting reflection in adult learning. In R. Edwards, A. Hanson, \& P. Raggatt (Eds.), Boundaries of adult learning (pp. 32-56). London: Routledge.

Bransford, J., Brown, A., \& Cockings, R. (Eds.). (2000). How people learn: Brain, mind, experience, and school. Washington, DC: National Academy Press.

Bybee, R., \& Sund, R. (1982). Piaget for educators (2nd ed.). Columbus, OH: Merrill.

Chlup, D. T., \& Collins, T. E. (2010). Breaking the ice: Using ice-breakers and reenergizers with adult learners. Adult Learning, 21(3-4), 34.

DeNeve, K. M., \& Heppner, M. J. (1997). Role play simulations: The assessment of an active learning technique and comparisons with traditional lectures. Innovative Higher Education, 21(3), 231-246. 
Deslauriers, L., Schelew, E., \& Wieman, C. (2011). Improved learning in a largeenrollment physics class. Science, 332(6031), 862-864.

Fadali, M. S., Robinson, M., \& McNichols, K. (2000, June). Teaching engineering to $K-12$ students using role playing games. Paper presented at the meeting of the American Society for Engineering Education, Washington, DC.

Francis, P. J., \& Byrne, A. P. (1999). Use of role-playing exercises in teaching undergraduate astronomy and physics. Publications of the Astronomical Society of Australia, 16(02), 206-211.

Joyner, B., \& Young, L. (2006). Teaching medical students using role play: Twelve tips for successful role plays. Medical Teacher, 28(3), 225-229.

Kiger, A. M. (2004). Teaching for health (2nd ed.). Edinburgh, UK: Churchill Livingstone.

Kruger, J., \& Dunning, D. (1999). Unskilled and unaware of it: How difficulties in recognizing one's own incompetence lead to inflated self-assessments. Journal of Personality and Social Psychology, 77(6), 1121.

Lane, C., Hood, K., \& Rollnick, S. (2008). Teaching motivational interviewing: Using role play is as effective as using simulated patients. Medical Education, 42(6), 637-644.

Mazur, E. (2009). Farewell, lecture? Science, 323(5910), 50-51.

Meyers, S. A. (2001). Conceptualizing and promoting effective TA training. In L. Prieto \& S. Meyers (Eds.), The teaching assistant training handbook: How to prepare TAs for their responsibilities (pp. 3-24). Stillwater, OK: New Forums Press.

Meyers, S. A., \& Prieto, L. R. (2000). Using active learning to improve the training of psychology teaching assistants. Teaching of Psychology, 27(4), 283-284.

Minner, D. D., Levy, A. J., \& Century, J. (2010). Inquiry-based science instructionwhat is it and does it matter? Results from a research synthesis years 1984 to 2002. Journal of Research in Science Teaching, 47(4), 474-496.

Oliveira, A. W. (2010). Improving teacher questioning in science inquiry discussions through professional development. Journal of Research in Science Teaching, 47(4), 422453.

Piccinin, S. J., Farquharson, A., \& Mihu, E. (1993). Teaching assistants in Canadian universities: An unknown resource. Canadian Journal of Higher Education, 23(2), 104117.

Sogunro, O. A. (2004). Efficacy of role-playing pedagogy in training leaders: Some reflections. Journal of Management Development, 23(4), 355-371.

Sturges, D., Maurer, T. W., \& Cole, O. (2009). Understanding protein synthesis: A roleplay approach in large undergraduate human anatomy and physiology classes. Advances in Physiology Education, 33(2), 103-110.

Turner, D. (1996). Role plays: A sourcebook of activities for trainers. London, UK: Kogan Page Publishers. 
Van Ments, M. (1999). The effective use of role-play: Practical techniques for improving learning. London, UK: Kogan Page Publishers.

Wedig, T. (2010). Getting the most from classroom simulations: Strategies for maximizing learning outcomes. PS: Political Science \& Politics, 43(03), 547-555.

Weimer, M., \& Lenze, L. F. (1997). Instructional interventions: A review of the literature on efforts to improve instruction. In R. P. Perry \& J. C. Smart (Eds.), Effective teaching in higher education: Research and practice (pp. 205-240). New York, NY: Agathon Press.

Wimer, D. J., Prieto, L. R., \& Meyers, S. A. (2004). To train or not to train; that is the question. In W. Buskist, B. C. Beins, \& V. W. Hevern (Eds.), Preparing for the new psychology professoriate: Helping graduate students become competent teachers (pp. 2-9). Syracuse, NY: Society for the Teaching of Psychology.

\section{Contact Information}

Priyanka Lekhi

Department of Chemistry

University of British Columbia

anka@chem.ubc.ca

Priyanka (Anka) Lekhi is an instructor in the Department of Chemistry, UBC. She teaches mainly general chemistry and analytical chemistry. Before working as an instructor, she was a facilitator of the Instructional Skills Workshop (ISW) for teaching assistants. The ISW aims to help its participants enhance their teaching and learning capabilities. Anka combines her role as an instructor in the department with her skills in facilitation to codevelop and co-facilitate the TA training workshop for all chemistry TAs.

Sophia Nussbaum is an instructor in the Department of Chemistry at UBC and a laboratory director in charge of over 4000 students and 60 TAs per year. She has been involved in TA training for 30 years and is particularly focused on developing TA training for international graduate students. 